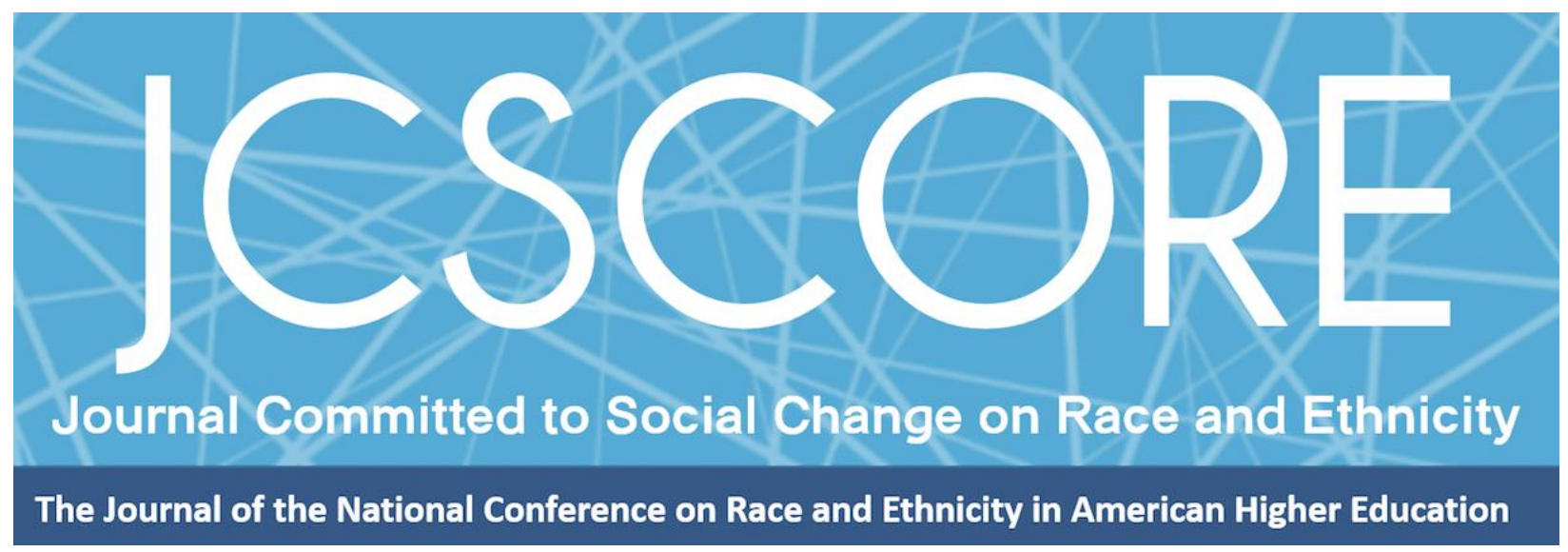

\title{
MULTIPLY MARGINALIZED: INDIGENOUS DEAF STUDENTS' EXPERIENCES IN HIGHER EDUCATION
}

\author{
Melanie McKay-Cody \\ Independent Scholar
}

Journal Committed to Social Change on Race and Ethnicity

Volume 6, Issue 1| 2020

\section{Copyright and Open Access}

(C) 2020 Melanie McKay-Cody

\section{cc) (i) (2)}

This work is licensed under a Creative Commons Attribution-NonCommercial-ShareAlike 4.0 International License. Permission of the authors is required for distribution and for all derivative works, including compilations and translations. Quoting small sections of text is allowed as long as there is appropriate attribution and the article is used for non-commercial purposes.

The Journal Committed to Social Change on Race and Ethnicity (ISSN 2642-2387) is published by the National Conference on Race and Ethnicity (NCORE), a production of the University of Oklahoma, in partnership with the University of Oklahoma Libraries. 


\section{Multiply Marginalized: Indigenous Deaf Students' Experiences in Higher Education}

Melanie McKay-Cody Independent Scholar

While there is a body of literature about the experiences of Indigenous college students, there is a complete lack of research on Indigenous Deaf college students (enrolled in either traditionally Deaf colleges, predominantly hearing colleges, or a combination of both). The question remains, what college experiences are Indigenous Deaf students having? This signed (American Sign Language) academic video-article examines the lived experience of ten Indigenous Deaf college students. In this study, these students' experiences are viewed through the Indigenous Deaf Methodologies framework coined by the author. The Indigenous Deaf Methodologies framework uses linguistic anthropology, Indigenous Methodologies (from hearing Indigenous researchers), and Deaf Epistemology (from white Deaf studies). This study focuses on the using of American Sign Language, tribal signed language, visual technologies, and the unique epistemological experiences of Indigenous Deaf students during their college years. This video-article explains the challenges such students face within colleges during a period spanning the 1970s to the today. The author provides recommendations for future programming and accessibility for the next generations of Indigenous Deaf college students.

To view this video-article please click here: Multiply Marginalized: Indigenous

Deaf Students' Experiences in Higher Education Or copy and paste the link to download video-article: https://www.youtube.com/watch?v=eeWLCcTONyo 